\title{
Prostate Stones
}

\author{
Hikmet Köseoğlu \\ Baskent University, F.E.B.U. \\ Turkey
}

\section{Introduction}

Being the only exocrine organ located in the midline, the prostate gland is a compound tubuloalveolar exocrine gland of the male reproductive system, locating just below the bladder. The term "prostate" comes (as commonly published) from Greek prostates, literally which means "someone who stands before someone or something" that is "president" or "principal" ; however in a recent paper on history of medical terminology it was suggested that in fact the term was originating from Greek parastates which means literally "someone who stands next to someone or something" or "companion" and was transformed into prostates due to misspelling and misinterpretation [1].

Embryologically, the prostate develops from the endodermal urogenital sinus which is an ambisexual embryonic rudiment. Endodermal urogenital sinus forms the prostate, prostatic urethra and bulbourethral glands in the males and the lower vagina and urethra in the females. The embryonic connective tissue surrounding endodermal urogenital sinus is called urogenital sinus mesenchyme. Under the influence of fetal androgens, epithelial outgrowths from the wall of the urogenital sinus move into the surrounding urogenital sinus mesenchyme forming prostatic glandular structure and the surrounding mesenchyme differentiates into smooth muscle cells and fibroblasts [2]. The secretory epithelium in this compound tubuloalveolar gland structure is mainly pseudostratified with transitional epithelium in the distal regions of the longer ducts. In the prostate gland acini, small round luminal hyaline masses called corpora amylacea may be found. With average diameter of $0.25 \mathrm{~mm}$, pink-purple to orange color these masses are believed to be related to epithelial cell desquamation and degeneration. They are composed of bundles of fibrils and containing mainly sulfated glycosaminoglycans [3]. Corpora amylacea are frequently seen in the benign acini of prostates of adult men however, they are rarely seen in prostate carcinoma [4].

\section{Prostate stones: Formation and structure}

In the literature, sometimes prostatic calculi are classified as either primary /endogenous calculi (developing within the acini of the gland) or secondary/exogenous (upper urinary system stone found in the prostatic urethra). Throughout this chapter, the terms "prostatic calculi" or "prostate stone" refers only to the stones developing within the acini of the gland (primary /endogenous calculi). 
The calcification of corpora amylacea within gland acini forms prostate stones. Prostate stones are predominantly found in the cephalic portion of the posterior lobe and in the larger ducts and acini of the lateral lobes of the prostate. Those within the acini are microscopic, while those within the ducts tend to be larger and are visible grossly. Suggested mechanism of the stone formation is the intra-prostatic reflux of urine which causes the deposition of hydroxyapatite crystallites in corpora amylacea and mineralization with calcium, leading to the formation of calculi [5-7]. Obstruction of the acini with calculi causes dilatation of acini and further increase in size of the stone with further precipitation of crystals. As well, the growing calculi itself or together with the inflammatory process, that it may initiate, may occlude other acini causing further stone formation. This way of formation leads to concentric calcification layers in the stone which is clearly seen under scanning electron microscope [8] (Figure 1). Such an occlusion mechanism might be responsible in cases of benign prostate hyperplasia. Observation of prostate stones located in the compressed true prostate adjacent to the adenomatous mass also supports this mechanism [9]. Prostate stones are not infection stones. Major calcium components of prostate stone are calcium phosphate or calcium oxalate, along with carbonate-apatite and hydroxyapatite $[7,8,10]$.
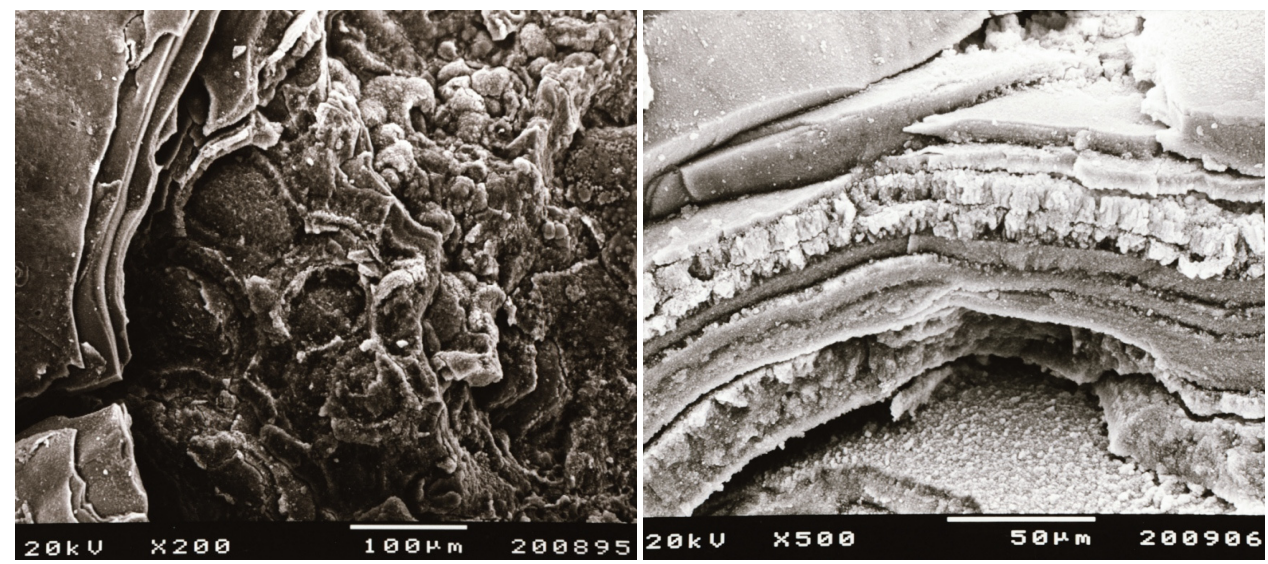

Fig. 1. Concentric calcification layers of prostate stone under scanning electron microscope (Personal archive of Koseoglu H, MD.)

Also, some pathological conditions like alkaptonuria and vitamin $\mathrm{D}$ overdose have been reported to cause prostatic calculi [11,12].

Prostate stones were classified structural morphology and mineral composition $[13,14]$ In one older study, stones taken from males with BPH were analyzed with scanning electron microscopy and energy dispersive type X-ray microanalyzer (EDAX) system for structure and element compositions. Mainly, elements of $\mathrm{Na}, \mathrm{Al}, \mathrm{Mg}, \mathrm{S}, \mathrm{P}, \mathrm{Ca}$ and $\mathrm{Zn}$ were identified. Stones were classified as type I and type II. Type I prostate stones have lobular surface made up of small spheres containing predominantly of sodium, sulfur, phosphorus, calcium, and zinc. Type II prostate stones have polyfaceted surface composed primarily of calcium phosphate in the form of hydroxyapatite crystals with high peaks of $\mathrm{P}$ and $\mathrm{Ca}$ [13]. In a rather recent study, the fine structure and mineral components prostate stones were 
analyzed by scanning electron microscopy, backscattered electron (BSE) imaging, energydispersive X-ray (EDX) microanalysis under an SEM and X-ray diffraction [14]. Main element composisiton was $\mathrm{Ca}, \mathrm{P}, \mathrm{Mg}, \mathrm{Zn}$ and $\mathrm{S}$. The prostate stones were classified into four groups (I-IV). Group I had the core deposits of calcospherites showing concentric rings and the laminated apatite deposits concentrically around the core. Group II had calcospherite deposits of apatite similar to group I with a rougher concentric formation. Group III similar to group I had the core of calcospherites and concentric laminated structures with wider peripheral region containing calcium oxalates spikes. Gorup IV had the core deposits with small hexahedral structures, identified as whitlockite, surrounded by incompletely concentric laminated bands of apatite. Group I-III were suggested to form from mineralization of corpora amylacea whereas group IV was suggested to form from mineralization of the organic substances, which might be derived from the simple precipitation of prostatic secretion [14].

Other than the crytalline structure of the prostate stones, their protein composition was studied with infrared spectroscopy and high-performance liquid chromatography combined with tandem mass spectrometry (LC/MS/MS) in the prostate stones taken form radical prostatectomy specimen of prostate cancer patients [15]. The predominant crystalline component was also confirmed as calcium phosphate in the form of hydroxyapatite. The most prevalent proteins were lactoferrin, myeloperoxidase, and S100 calcium-binding proteins A8 and A9. Others were multiple proteins found in neutrophil granules. All these proteins act in acute inflammatory pathways. The authors suggested that this may indicate past inflammatory events in the prostate [15].

\section{Epidemiology}

The data in the literature on the prevalence of prostatic calculi is inconclusive. In a report of postmortem study using microradiographic examination, the intraprostatic calcifications were found to be prevalent as high as $71 \%$ [16]. In one study using transrectal ultrasonography prostatic calculi were detected in $198(40.7 \%)$ of the 486 screened man with a mean age of $61.9+/-0.4$ years (range 29 to 89) [17]. In another study using transrectal ultrasonography prostatic calculi were detected in $799(51.1 \%)$ of 1563 with a younger mean age of $49.5+/-5.4$ years (range 40 to 59) [18]. Again, in another study done with transrectal ultrasonography prostatic calculi were detected with a similar ratio of $41.77 \%$ [19].

However, in another recent study using transabdominal ultrasonography (TRUS only in $16.83 \%$ of cases) the prevalence was found to be low as $7.35 \%$ in a screened adult group with a mean age of 40.9 (range 21-50) years [20]. The methodological difference may be a reason of low prevalence. But, in that study the patients were chosen among a population of nonconsecutive 1374 young men that attended the hospital outpatient clinics for several reasons. It is worthy to note that in other studies using transrectal ultrasonography, above mentioned, the study population was chosen from consecutive patients attending urology clinics for routine checkup of PSA and DRE evaluation or with complaints of LUTS or chronic prostatitis/chronic pelvic pain syndrome. That may also be a reason for the high difference between prevalence of the studies.

The youngest patient reported was 4 year old and in that patient the calculi was thought to be related to vitamin $\mathrm{D}$ overdose [11]. 


\section{Clinical importance}

Prostate stones are generally clinically asymptomatic, when symptomatic the symptoms are generally related to lower urinary tract symptoms $[18,19]$. The prostatic calculi are mostly found incidentally during diagnostic workup for any urological complaint. In the CT scans, pelvic/transrectal ultrasonography or KUB X-scans they may be found incidentally (Figures 2; 3). They are also frequently encountered during transurethral resection of the prostate [8] (Figure 4). In benign prostatic hyperplasia, prostate stones tend to be located in the compressed true prostate, adjacent to the adenomatous mass [9]. Therefore, during transurethral resection of the prostate, prostate stones are rather observed when the depth of resection increased and thus they act sometimes as a border for prostate capsule during TURP.

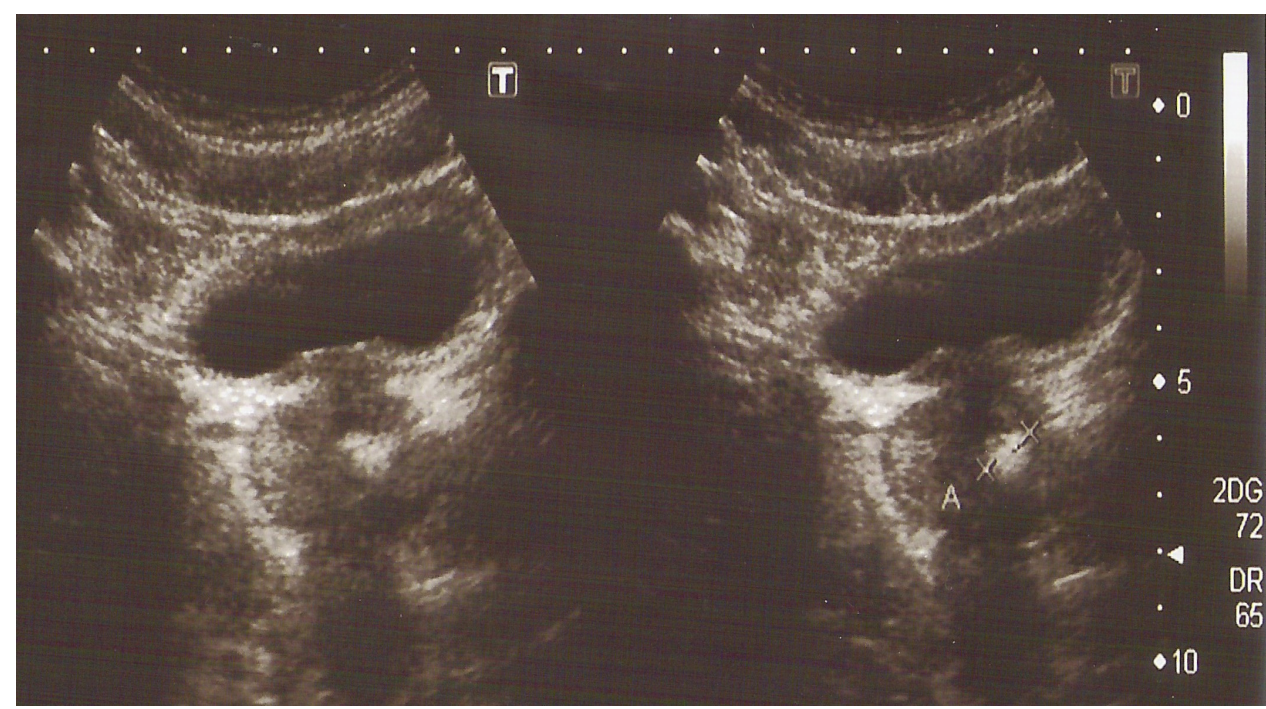

Fig. 2. Pelvic ultrasonography showing prostate stone in the prostate gland (Personal archive of Koseoglu H, MD.)

The presence of large prostatic calculi has been shown to be a significant associated factor of moderate LUTS [18]. In another study, patients with prostate stones were reported to have more severe LUTS and decreased the maximum urinary flow rates compared to patients without prostate stones. However, based on multivariate analyses, prostate stone was not an independent predictive factor of severe LUTS [19]. Rather, older age and larger prostate volume were independent predisposing factors for prostate stone [19].

Larger prostate stones were suggested to have a relation with clinical prostatitis/ chronic pelvic pain syndrome [20]. Histopathological inflammation with varying degrees of severity may accompany prostate stones [8]. However, it is unclear whether inflammation is a cause or the result of calculi formation. The prostatic stones do not raise PSA, which increases with inflammation, indirectly indicating that these calculi do not increase inflammation [17]. On the other hand, intra-prostatic reflux related to prostate stone formation may play a role in the accompanying inflammation of prostate gland. In a study using anti-nanobacterial agent it was shown that prostatic stones diminished 50\% ultrasonographically and chronic 
prostatitis symptom scores were decreased [21]. However, there was no relationship between chronic prostatitis symptom scores and prostatic calculi or level of the histological prostatic inflammation [21].

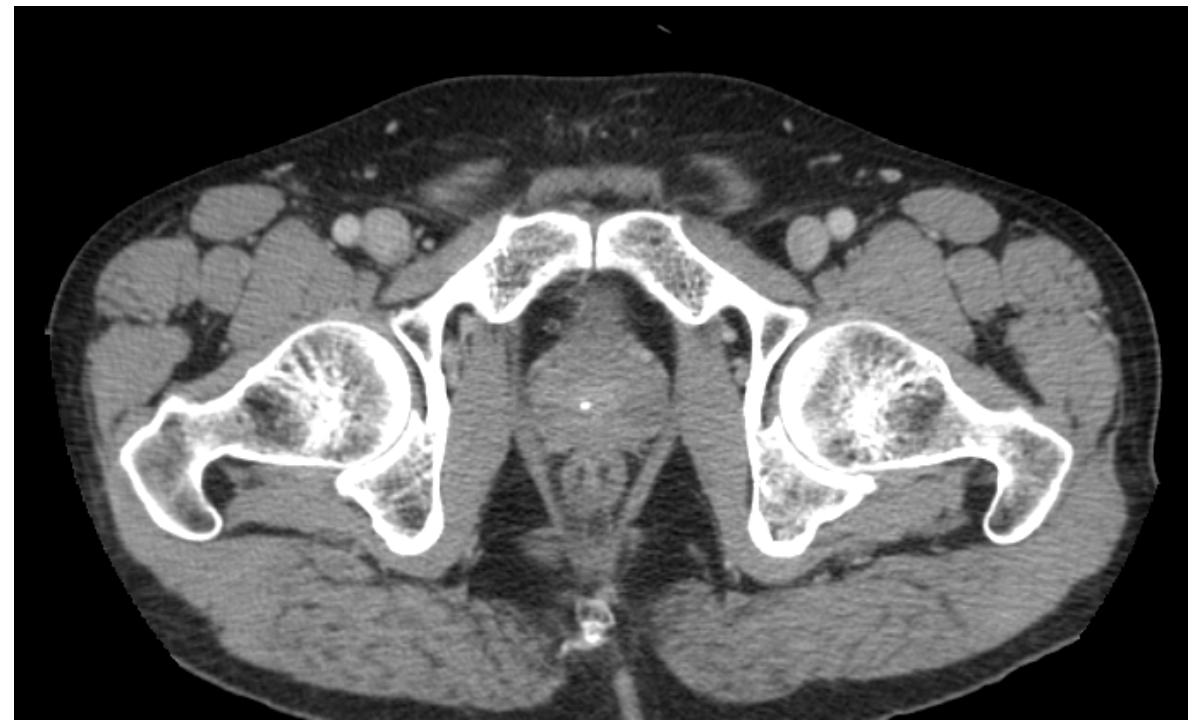

Fig. 3. Pelvic CT scan showing prostate stone in the prostate gland (Personal archive of Koseoglu H, MD.)

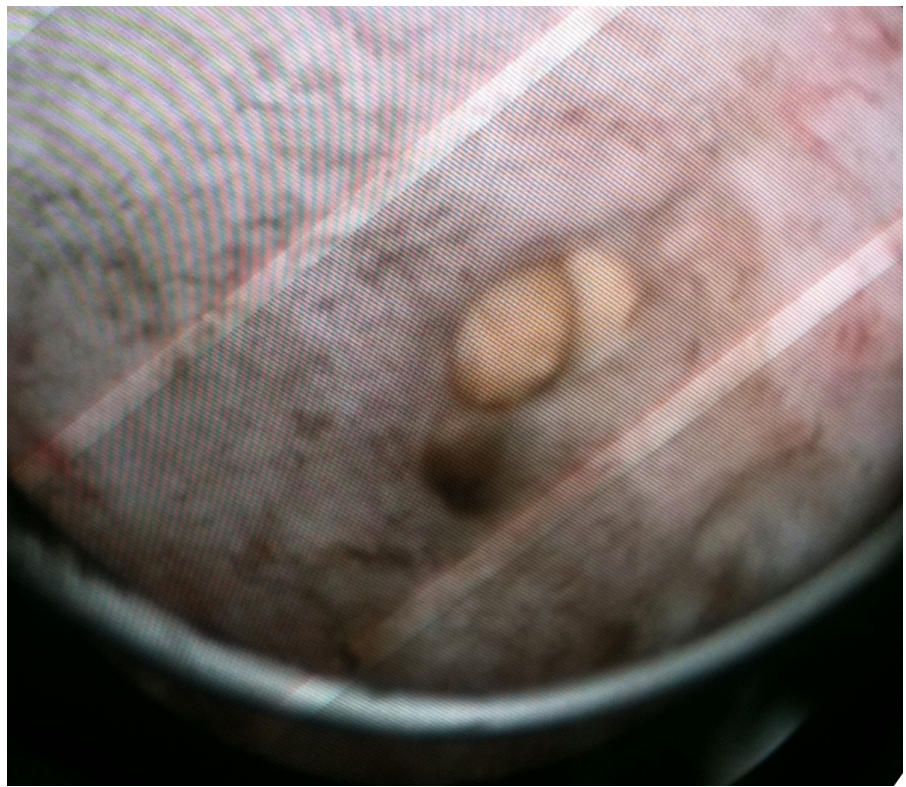

Fig. 4. Prostate stones encountered during TUR-P ( Personal archive of Koseoglu H, MD.) 
In the literature, there are few case reports related to large prostate stones causing infravesical obstruction [22-27].

No direct or indirect relationship has been reported between prostate stone and prostate cancer. Actually the incidence of corpora amylacea in adenocarcinoma is low [5].

\section{Management of prostate stones}

Though prostate stones are generally accepted as clinically silent, few cases were reported to have surgical intervention for severe obstruction caused by large prostate stones. Surgical procedures like open transvesical prostate stone extraction [23], endoscopic extraction $[12,22,25]$, open prostatolithotomy [26] and even radical prostatectomy [27] have been performed to extract these stones.

As mentioned above ,in one study anti-nanobacterial agent was studied in patients with chronic prostatitis and prostate stones and it was shown that prostate stones diminished $50 \%$ ultrasonographically [21]. But, yet this is to be clarified by further studies.

\section{Summary}

In the prostate gland acini, the small round luminal hyaline masses are called corpora amylacea and their calcifications form prostate stones. Suggested mechanism is the intraprostatic reflux of urine which causes the deposition of hydroxyapatite crystallites in corpora amylacea and mineralization with calcium. Some pathological conditions like alkaptonuria and vitamin D overdose have been reported to cause prostatic calculi. Major calcium components of prostate stone are calcium phosphate or calcium oxalate, along with carbonate-apatite and hydroxyapatite, whereas most prevalent proteins are lactoferrin, myeloperoxidase, and S100 calcium-binding proteins A8 and A9. Being predominantly located in the cephalic portion of the posterior lobe and in the larger ducts and acini of the lateral lobes of the prostate, prostate stones are mostly clinically asymptomatic. When it is symptomatic the symptoms are generally related to lower urinary tract symptoms. Few cases with large prostate stones causing infravesical obstruction and necessitating surgical intervention have been reported. No direct or indirect relationship has been reported between prostate stone and prostate cancer.

\section{References}

[1] Marx FJ, Karenberg A (2009) History of the term prostate. Prostate. 69:208-213.

[2] Cunha GR, Ricke W, Thomson A, Marker PC, Risbridger G, Hayward SW, Wang YZ, Donjacour AA, Kurita T(2004) Hormonal, cellular, and molecular regulation of normal and neoplastic prostatic development. J Steroid Biochem Mol Biol. 92:22136.Review.

[3] Cohen RJ, McNeal JE, Redmond SL, Meehan K, Thomas R, Wilce M, Dawkins HJ (2000) Luminal contents of benign and malignant prostatic glands: correspondence to altered secretory mechanisms. Hum Pathol. 31:94-100.

[4] Christian JD, Lamm TC, Morrow JF, Bostwick DG (2005) Corpora amylacea in adenocarcinoma of the prostate: incidence and histology within needle core biopsies. Mod Pathol.18: 36-39. 
[5] Moore RA (1936) Morphology of prostatic corpora amylacea. Arch Pathol. 22: 24-40.

[6] Hassler O (1968) Calcification in the prostate gland and adjacent tissues. A combined biophysical and histological study. Path Microbiol. 31: 97-107.

[7] Magura CE, Spector M (1979) Scanning electron microscopy of human prostatic corpora amylacea and corpora calculi, and prostatic calculi. Scan Electron Microsc 3: 713720 .

[8] Köseoğlu H, Aslan G, Sen BH, Tuna B, Yörükoğlu K (2010) Prostatic calculi: silent stones. Actas Urol Esp. 34:555-559.

[9] Young HH (1934) Prostatic calculi. J Urol.32:660-709.

[10] Ramires TC, Ruiz JA, Gomez AZ et al (1980) A crystallographic study of prostatic calculi. J Urol. 124: 840-843.

[11] Izzidien AU (1980) Prostatic calcification in a four year old boy. Arch Dis Child. 55: 963968.

[12] Strimer RM, Worn LJ (1977) Renal and vesical prostatic calculi associated with ochronosis. Urology.10: 42-34.

[13] Vilches J, Lopez A, De Palacio L, Muñoz C, Gomez J (1982) SEM and X-ray microanalysis of human prostatic calculi. J Urol.127:371-373.

[14] Kodaka T, Hirayama A, Sano T, Debari K, Mayahara M, Nakamura M (2008) Fine structure and mineral components of primary calculi in some human prostates. J Electron Microsc (Tokyo).57:133-141.

[15] Sfanos KS, Wilson BA, De Marzo AM, Isaacs WB (2009) Acute inflammatory proteins constitute the organic matrix of prostatic corpora amylacea and calculi in men with prostate cancer. Proc Natl Acad Sci U S A.106:3443-3448.

[16] Thomas BA, Robert JT (1927) Prostatic calculi. J Urol.18: 470-493.

[17] Lee SE, Ku JH, Park HK, Jeong CK, Kim SH (2003) Prostatic calculi do not influence the level of serum prostate specific antigen in men without clinically detectable prostate cancer or prostatitis. J Urol.170: 745-748.

[18] Kim WB, Doo SW, Yang WJ, Song YS (2011) Influence of prostatic calculi on lower urinary tract symptoms in middle-aged men. Urology.78:447-449.

[19] Park SW, Nam JK, Lee SD, Chung MK (2010) Are prostatic calculi independent predictive factors of lower urinary tract symptoms? Asian J Androl.12:221-226.

[20] Geramoutsos I, Gyftopoulos K, Perimenis P, Thanou V, Liagka D, Siamblis D, Barbalias G (2004) Clinical correlation of prostatic lithiasis with chronic pelvic pain syndromes in young adults. Eur Urol.45:333-337.

[21] Shoskes DA, Thomas KD, Gomez E (2005) Anti-nanobacterial Therapy for men with chronic prostatitis/chronic pelvic pain syndrome and prostatic stones: preliminary experience. J Urol. 73: 474-477.

[22] Hayakawa T, Saito T, Mitsuya H, Kojima M, Hayase Y (2001) [A case of infravesical obstruction caused by prostatic stones as diagnosed by transrectal ultrasonography at voiding]. Hinyokika Kiyo.47.289-292.

[23] Spittel RL (1915) Calculi of the Prostate. Br Med J.21;2(2851):289-91

[24] Kamai T, Toma T, Kano H, Ishiwata D (1999) Urethral obstruction due to protruding prostatic calculi. J Urol.162: 163-164.

[25] Bedir S, Kilciler M, Akay O, Erdemir F, Avci A, Ozgok Y (2005) Endoscopic treatment of multiple prostatic calculi causing urinary retention. Int J Urol.12: 693-695. 
[26] Shah SK, Chau MH, Schnepper GD, Lui PD (2007) Open prostatolithotomy for the management of giant prostatic calculi. Urology.70:1008.e9-10.

[27] Virgili G, Forte F, Sansalone S, Attisani F, De Carolis A, Di Stasi SM, Vespasiani G (2004) Radical prostatectomy as unique chance for huge prostatic stones.Arch Ital Urol Androl. 76:171-172. 
(C) 2012 The Author(s). Licensee IntechOpen. This is an open access article distributed under the terms of the Creative Commons Attribution 3.0 License, which permits unrestricted use, distribution, and reproduction in any medium, provided the original work is properly cited. 